\title{
Practice and Exploration of Teaching Reform of Object-Oriented Programming Course Based on CDIO Concept
}

\author{
Guangxuan Chen ${ }^{1,}$, Guangxiao Chen ${ }^{2, b}$ \\ ${ }^{1}$ Zhejiang Police College, Hangzhou, 310053, China \\ ${ }^{2}$ Universidad Carlos III de Madrid, Madrid, Spain \\ aemail: chenguangxuan@zjjcxy.cn, ${ }^{\mathrm{b} e m a i l: ~ r e x 1220 @ f o x m a i l . c o m ~}$
}

\author{
Keywords: Teaching Reform; CDIO; Engineering Education; OOP
}

\begin{abstract}
This work analyzed the problems existed in object-oriented programming teaching, and then proposed a new object-oriented programming teaching mode that draws lessons from the concept of CDIO engineering education. The new teaching mode is correspond to the four abilities of CDIO and explained the teaching objective reconstruction, teaching content organizing, teaching method improving and assessment method reform. Practice shows that this CDIO concept based teaching reform can effectively arouse the enthusiasm of the students and improve their comprehensive practical abilities.
\end{abstract}

\section{Introduction}

In the era of highly developed information technology, there's an increasingly demand over professionals of computer science, information security, communication, and so on. Nowadays, as the higher education of China entered into the stage of popularized education, computer education is facing with new development opportunities along with new challenges. Like the common polytechnic universities and vocational colleges, public security colleges are also undertaking the missions of training professional and technical personnel, i.e., these colleges have to cultivate a large number excellent professional network security and law enforcement personnel for the grass-roots public security departments. As for applied personnel, they should possess the ability of applying the professional knowledge and skills to the social practice. Applied personnel is meeting the needs of current society and also the network security and law enforcement major meets the position of the public security serving the local public security departments.

As one of the most important specialized courses of computer science and network security and law enforcement, Object-oriented programming (OOP) is a programming paradigm based on the concept of "objects", which are data structures that contain data, in the form of fields, often known as attributes; and code, in the form of procedures, often known as methods [1, 2]. Significant object-oriented languages include Objective-C, C++, Java, C\#, Python, Ruby, Smalltalk, PHP, Swift and Delphi [1].

However, due to the specialties of the students and teaching mechanism, a series of problems emerged up in the teaching process of the object-oriented programming: (1) Over-emphasized on theoretical teaching while underestimate practice teaching. Due to the limited teaching hours and other reasons, the teachers usually adopt force-feeding method in the classroom. This teacher-centered teaching method greatly limited the participation of the students and has little effect in improving students' practical abilities. (2) Lack of practical skill and experience. Duo to various factors, most college teachers with master's degree and doctorate took the teaching positions directly when they graduated. So, lack of experience in large project development is the unarguable reality, which leads to less efficient in guiding students in engineering practice. (3) Object-oriented programming is single and without mature curriculum system. $\mathrm{C}++$ and Java are very popular in the curriculum system of computer science and network security and law enforcement. However, the lack of follow-up courses and cases make students can't quite understand the marrow of object-oriented programming, and thus can't meet the needs of the specific positions. Therefore, it is imperative for us to reform the curriculum system and teaching 
according to the reality of the specific college so as to cultivate qualified personnel to meet the needs of the society.

\section{Spoon-Feeding Method in OOP Class}

As is first introduced by N.A. Kaiipob, a famous educator of Former Soviet Union, spoon-feeding methods is prevalent in all kinds of classroom. Object-Oriented Programming course, like many other subjects, use spoon-feeding methods where students are imposed on some knowledge and their initiative cannot find its place. As a highly practical course, OOP requires the students do a lot of engineering practice after they familiar with the basic knowledge. However, the spoon-feeding method is just tell the "what", do not tell you or not clear "why", let you go rote, so you know "how to do" is not firm, relies entirely on memory.

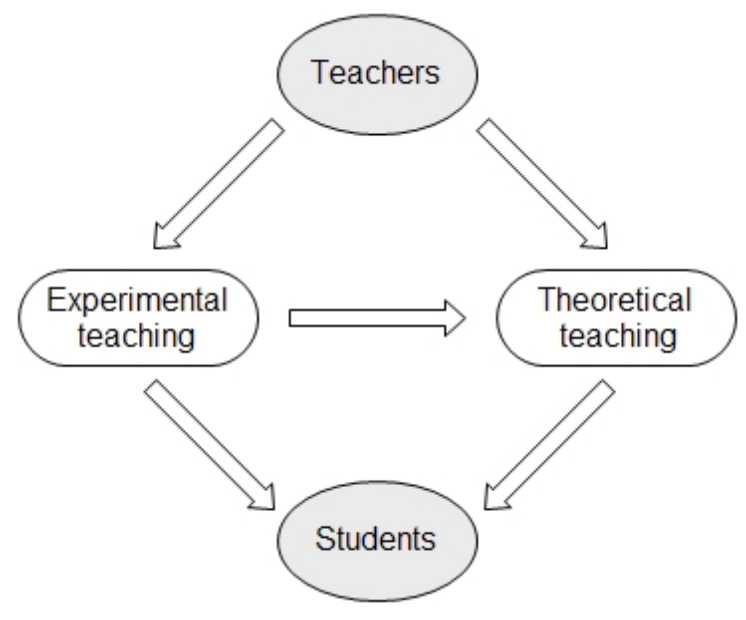

Fig.1. Spoon-feeding teaching mode in OOP class

Figure 1 shows a typical spoon-feeding teaching mode in OOP class. Most of the teachers are just graduated with little OOP development experience. The main teaching methods are experimental and theoretical teaching which are directly pushed to the students. Several representative phenomena can be seen in the class:

(1) Teacher-led teaching where students learn passively;

(2) Emphasized on simple memory and repeated training while weakening the thinking and understanding and practical ability;

(3) Students are forced to sitting in the classroom rather than interested in the course.

The disadvantages of spoon-feeding methods in OOP course are obvious. Students' creativity is greatly stifled and they are trained to not have their own ideas. Thus, few of them can put the requirement of the user into computer program. In turn, this kind of teaching method for OOP class is proved to be a failure.

\section{CDIO Initiative}

The CDIO Initiative is an innovative educational framework for producing the next generation of engineers [3]. Here, CDIO is a trademarked initialism for Conceive - Design - Implement - Operate and the CDIO concept was originally conceived at the MIT in the late 1990s. While, CDIO initiative that provides students with an education stressing engineering fundamentals set in the context of Conceiving - Designing - Implementing - Operating real-world systems and products was formally founded by MIT in collaboration with Chalmers University of Technology, Linköping University and the Royal Institute of Technology in 2000 [3, 4].

$\mathrm{CDIO}$ is based on a commonly shared premise that engineering graduates should be able to: Conceive-Design-Implement-Operate complex value-added engineering systems in a modern team-based engineering environment to create systems and products[5]. The vision of the CDIO-based education can be summed as follows [5-7]: 
Table 1 Vision of CDIO-based education

\begin{tabular}{|l|l|}
\hline Curriculum Design & $\begin{array}{l}\text { Organized around mutually supporting courses, } \\
\text { but with CDIO activities highly interwoven }\end{array}$ \\
\hline Engineering Practice & Rich with student design-build-test projects \\
\hline Professional Skills & $\begin{array}{l}\text { Integrating learning of teamwork, } \\
\text { communication, and so on }\end{array}$ \\
\hline Experiential Learning & Featuring active and experiential learning \\
\hline Ability proof & $\begin{array}{l}\text { Constantly improved through quality assurance } \\
\text { process with higher aims than accreditation }\end{array}$ \\
\hline
\end{tabular}

\section{CDIO Based Teaching Reform for OOP}

In view of the problems existing in OOP course, we draw on the CDIO engineering education concept and then propose a new teaching method that corresponding to the four abilities that CDIO concept advocated, and explore the reform measures through reconstruction of teaching objectives, organization of teaching content, improvement of teaching method and innovation of assessment method. Figure 2 shows a typical CDIO concept based teaching mode in OOP class.

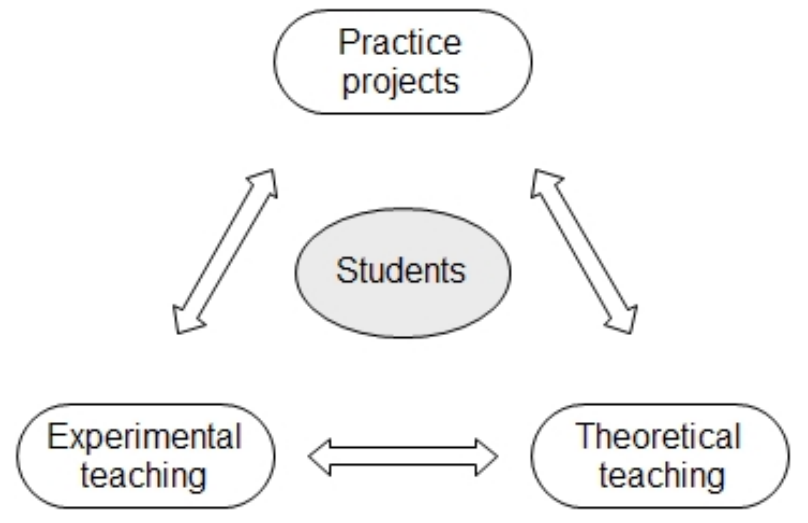

Fig.2. CDIO concept based teaching mode in OOP class

(1) Recognize the teaching objective of OOP course based on CDIO

The traditional teaching objective of OOP course mainly emphasized on the grasping of the syntax and rules of the programming language, which is far from of the requirement of the engineering practice. So, the first and far most task is to re-orientate the teaching objective and expand exploration on mastering of basic knowledge, fostering abilities of program design and development, enhancing of teamwork abilities, fostering ability of software testing and professional quality.

(2) Develop the integrated teaching based engineering practice

Start from the classic engineering cases (such as small fun games, project cases, etc.), guide the students methodically master and apply basic programming knowledge to improve their practical abilities and gradually enhance their initiatives. Case based integrated teaching can overcome the drawbacks of spoon-feeding method and make the teaching content more intuitive. This not only can make full use of time, but also can avoid the embarrassment of learning to useless.

(3) Carry out programming ability assessment based on the four layers of standard CDIO abilities

In order to assess whether the students have reached to the teaching objective, the reform will observe the students' comprehensive abilities as basic knowledge of engineering, individual capability, interpersonal skills and engineering system ability. OOP is a highly practical course which should emphasize on the enhancing of practical engineering ability rather than the simple memory of the syntax of the language. The specific ability assessment includes the proficiency of 
operating the software development toolkits, analytical skills of program structure and semantic analysis ability, normative of programming procedure, teamwork, requirement analysis skills, and so on. The entire assessment will be reflected in each process of the engineering practice.

(4) Enhance the teacher's ability under the systematic and sustainable requirements of CDIO

The reform will set guide for the implementation and assessment of the teaching mode under CDIO standard, widen the teachers' participation in engineering projects and enrich their practical experience, enhance teacher's project and system construction ability so as to promote the role of teacher in the integrated teaching. Meanwhile, it uses active and experimental learning method to promote the integration of teachers' professional learning, engineering practice and teaching, so as to enhance students' four layers of CDIO based capabilities.

\section{Conclusion}

Modern software engineering requires the learners not only have a good command of theoretical programming knowledge, but also practical experience which can only be acquired through engineering practice. Thus, the traditional spoon-feeding method in OOP class is increasingly shows its drawbacks. CDIO concept based teaching for OOP has a curriculum organized around mutually supporting courses and rich with student design-build-test projects. It integrates learning of professional skills such as communications and teamwork. Active and experiential learning are highly emphasized. Meanwhile, both the teaching and learning are constantly improved through quality assurance process with higher aims than accreditation. Practice shows CDIO concept based teaching reform can effectively promote the interaction between students and teachers, and arouse the enthusiasm of the students and improve their comprehensive practical abilities and professional skills.

\section{Acknowledgement}

In this paper, the research was sponsored by the Classroom Teaching Reform Program of Zhejiang Provincial Higher Education of year 2015 (No. kg2015468) and Educational Technology Planning Program of Zhejiang Province of year 2015 (No. JB058).

\section{References}

[1] Wikipedia, Object - Oriented Programming, https : // en. Wikipedia .org / wiki / Object oriented _ programming, (2015)

[2] Kindler E, Krivy I, Object-Oriented Simulation of systems with sophisticated control, International Journal of General Systems. (2011) 313-343.

[3] Wikipedia, CDIO, https://en.wikipedia.org/wiki/CDIO, (2015)

[4] Information on http://www.cdio.org/cdio-collaborators

[5] Information on http://www.cdio.org/cdio-vision

[6] Enxia Yang, Fankai Kong, Heping Liu, Yonggang Pang, Lixia Ying. Reform of machinery foundation course based on CDIO concept [J]. Journal of Higher Education, 2016 (1) 119-120.

[7] Wei Sun. The application of CDIO education mode in software engineering teaching [J]. Telecom World, 2015 (11) 264-265. 